\title{
ENSINO REMOTO E ISOLAMENTO SOCIAL: POLÍTICAS DE CONTENÇÃO DA PANDEMIA QUE NÃO ASSISTEM ÀS DEMANDAS SOCIAIS DE GÊNERO E RAÇA
}

\author{
REMOTE EDUCATION AND SOCIAL ISOLATION: POLICIES TO CONTAIN THE \\ PANDEMIC THAT DO NOT MEET THE SOCIAL DEMANDS OF GENDER AND RACE
}

\section{Bruno Luiz Silveira de Castro}

RESUMO: Não é segredo para ninguém que a sociedade brasileira apresenta distinções quanto ao acesso à dignidade e a cidadania. Achar que somente por ter um artigo na Constituição Federal brasileira que versa sobre todos serem iguais perante a lei é suficiente, é ingenuidade ou mau-caratismo. Diversas políticas são propostas e a grande maioria delas não visam as diferenças entre as raças e os gêneros. Apesar de vários movimentos sociais chamarem a atenção para o assunto. Apesar de a Agenda 2030 trazer objetivo e metas para o alcance da igualdade de fato através de políticas que observam as necessidades de cada um. É notório que medidas governamentais propostas emergencialmente não atendem as necessidades básicas de todos. Visto isso, este ensaio tem por objetivo demonstrar que ensino remoto e isolamento social são medidas políticas de contenção da disseminação da Covid-ı, mas que não visam as diferenças entre gênero e raça da sociedade brasileira.

Palavras-chave: Igualdade. Equidade. Justiça. Covid-ıg.

ABSTRACT: It is no secret that Brazilian society presents distinctions when it comes to access to human dignity and citizenship. To believe that just having an article in the Brazilian Federal Constitution that states that everyone is equal before the law is enough is naivety or even dishonesty. The vast majority of the proposed policies don't aim at the differences between races and genders, even though several social movements call attention to the subject, such as Agenda 2030 which brings objectives and goals to achieve in fact equality through policies that take into account the needs of each individual. It is clear that government measures taken on an emergencial basis do not meet everyone's basic needs. In view of this, this essay aims to demonstrate that remote education and social isolation are political measures to contain the dissemination of Covid-I9, but that they do not aim at the differences between gender and race in Brazilian society.

Keywords: Equality. Equity. Justice. Covid-ı9.

I 1 Estudante do Programa de Pós-Graduação em Práticas de Desenvolvimento Sustentável - Mestrado Profissional - Instituto de Florestas - Universidade Federal Rural do Rio de Janeiro 


\section{INTRODUÇÃO}

O quadro caótico ainda persiste e não é segredo para ninguém o momento em que a sociedade está vivendo. O cenário é catastrófico e está longe de acabar. Desde que a Organização Mundial da Saúde - OMS, por meio de seu Diretor-Geral Tedros Adhanom Ghebreyesus anunciou o status de pandemia do Covid-19 (OPAS, 2020) algumas medidas foram tomadas pela grande maioria dos países, alguns rapidamente organizaram no combate, já outros tardiamente tomaram providências. Entretanto, existem países que não adotaram medidas para com o enfrentamento da disseminação do SARS-CoV-2, agente etiológico causador da Covid-r9, (BITTENCOURT, 2020).

Aqui no Brasil, algumas medidas foram tomadas a cunho de tentar diminuir a circulação de pessoas na rua. Diversos lugares fecharam as portas e começaram a trabalhar através do regime de home office. A educação (de uma forma geral), sendo pública ou privada, foi a primeira delas através de uma portaria que o Ministério da Educação - MEC, por meio de seu Ministro Abraham Weintraub, Portaria n. ${ }^{\mathrm{o}}$ 343, de 17 de março de 2020: Dispões sobre a

suspensão das aulas presenciais por aulas em meios digitais enquanto durar a situação de 944 pandemia do Novo Coronavírus - COVID-I9 (BRASIL, 2020b).

Outra medida tomava por vários estados federativos da União baseando-se na Portaria do Ministério da Saúde (BRASIL, 2020..$^{a}$ ), foi o isolamento social em casa. Mesmo que não tenha apresentado eficácia ou taxa suficiente para um retorno interessante na diminuição dos níveis de disseminação no vírus entre a população, ficando por volta de 40 a 50\% na maior parte dos meses (INLOCO, 202I), muitos cidadãos aderiram ao isolamento social e encontrase sob ele até então, saindo o mínimo possível.

Entretanto, uma boa parcela da população brasileira não consegue de fato exercer as políticas supracitadas, pois não apresentam condições mínimas de moradia e/ou não executam atividade econômica que os permitem ficar em home office, logo, em isolamento social. Assim, os brasileiros esbarraram em políticas que não visaram de forma alguma as desigualdades de gênero e raça. 
O objetivo deste ensaio é demonstrar que ensino remoto e isolamento social são medidas políticas de contenção da disseminação da Covid-ı, mas que não visam as diferenças entre gênero e raça da sociedade brasileira.

\section{METODOLOGIA}

A metodologia usada foi a revisão bibliográfica (CERVO; BERVIAN; SILVA, 2007) buscando informações pertinentes ao assunto em questão em artigos científicos, documentos da União, sites de internet que promovem informações voltadas para tal, além de reportagens sobre a realidade da sociedade brasileira, para ter sustentação e referência teórica.

A proposta é trazer para o debate através de fundamentação científica a necessidade de exploração do entendimento de que as políticas adotadas, num primeiro momento parecem promover benefícios para toda a sociedade, mas que quando analisadas separadamente, são outros aspectos que aparecem e demandam atenção.

\section{A RAÇA E A PANDEMIA}

O Brasil é um país miscigenado. O seu processo de colonização promoveu a entrada de vários povos de diferentes partes do mundo, onde antes, só existiam os nativos, chamados índios pelos brancos que aqui chegaram tardiamente. Pois, então, hoje, denominados Povo Indígena, o qual abrange todas as várias etnias originárias do território local, nacional. Durante o processo de colonização do solo brasileiro, várias raças cruzaram o oceano Atlântico. Umas em busca de riquezas como os europeus, outras trazidas às forças como os africanos. Mas tardiamente, os asiáticos também vieram e estabeleceram-se por aqui.

Obviamente, que este não se trata de um ensaio histórico, mas faz-se necessário um breve relato sobre o processo que promoveu a tão característica miscigenação do povo brasileiro. Com o passar dos anos e o desenrolar da sociedade brasileira, diferenças foram se acentuado e por mais que durante a República, algumas medidas foram tomadas para diminuir a distância entre as camadas sociais, ainda é absurdamente distante as realidades que 
envolvem todos os brasileiros. Esse abismo é herança da escravidão e como se deu o seu fim no processo histórico brasileiro.

Voltando ao dia a dia da sociedade brasileira. Num quadro pandêmico, medidas foram tomadas. Medidas que de forma alguma visaram as diferenças de raça. Mas antes de comentar sobre o ensino remoto, precisamos de um conceituar raça e segundo Santos et al. (2010):

\footnotetext{
Raça refere-se ao âmbito biológico; referindo-se a seres humanos, é um termo que foi utilizado historicamente para identificar categorias humanas socialmente definidas. As diferenças mais comuns referem-se à cor de pele, tipo de cabelo, conformação facial e cranial, ancestralidade e genética. Portanto, a cor da pele, amplamente utilizada como característica racial, constitui apenas uma das características que compõem uma raça (SANTOS et aI., 2010, p. 4).
}

A complexidade da raça não pode se resumir à cor da pele, ela é muito maior. É muito mais representativa.

Uma das medidas tomadas pelo governo brasileiro foi a substituição do ensino presencial pelo ensino remoto enquanto durar a pandemia do Covid-I9 por meio da Portaria $\mathrm{n}$ o 343 , de 17 de março de 2020 (BRASIL, 2020b). A princípio um grande problema de circulação de pessoas e permanência delas em lugares fechados por mais de quatro horas diárias havia sido resolvido.

Entretanto, o que chama a atenção para quem vive a educação de perto, principalmente a educação pública brasileira é justamente, na realidade brasileira, ser possível que todas(os) as(os) alunas(os) tenham acesso remoto garantido como um passe de mágica, com a simplicidade de uma portaria, com a comodidade de uma assinatura.

Logo, para aqueles que não têm noção da realidade brasileira, um grande problema de circulação e aglomeração em lugares fechados poderia ser evitado com essa Portaria (BRASIL, 2020b) importantíssima como a supracitada. Entretanto, no Brasil a situação é crítica e nem todos os brasileiros apresentam condições de terem acesso aos equipamentos necessários como computador, notebook, notebook ou smartphones (TOKARNIA, 2020a), além da necessária internet (VALENTE, 2020) para que as(os) alunas(os) conseguissem ter acesso às aulas e materiais disponibilizados na rede pelos(as) Professor(as) e Escola. 
Muitas escolas até mantêm impressões para entregar as(os) alunas(os) (ANTUNES, 2020), mas diversos estudantes só conseguem chegar às escolas através de transporte escolar (DANIEL, 2020).

Numa análise dura da realidade de poder aquisitivo do cidadão brasileiro, cerca de $75 \%$ dos mais pobres do país são pretos, já os brancos ocupam por volta de 70\% dos mais ricos do país (MADEIRO, 2019).

Logo, percebe-se que em questões de raça, a educação remota não manteve o padrão do ensino presencial, o qual já não apresentava um padrão interessante e também é bastante desigual quando consideramos a questão financeira, pois entre os mais pobres, o analfabetismo é vinte vezes maior (BRASIL, 2003) e como supracitado, a população mais pobre é esmagadoramente representada pelos brasileiros de pele preta.

Dentre os dezessete objetivos de desenvolvimento sustentável - ODS, há o ODS 4, o qual versa sobre assegurar a educação inclusiva e equitativa de qualidade e promover oportunidades de aprendizagem ao longo da vida para todos (AGENDA 2030, 2015), é notório que o governo federal brasileiro está longe de conseguir atingir este ODS quanto ao ensino presencial, para o ensino remoto o abismo é colossal.

Outra política adotada foi o isolamento social por meio da Portaria n.o 356 , de in de março de 2020 (BRASIL, 2020a). O isolamento social é necessário para brecar a diminuição da circulação do vírus, já que se tratando de um contágio direto e indireto (BULUT; KATO, 2020), quanto mais as pessoas estiverem longe uma das outras, menos o vírus irá circular (WHO, 2021). Logo, menos vítimas. Entretanto, a realidade social do Brasil não é bem assim.

Num corte básico para entender quantos brasileiros vivem em média no mesmo lar (TOKARNIA, 2020b), quantos cômodos tem por imóvel brasileiro (FOLHAPRESS, 2020) e quantos de fato ficaram em home office (LISBOA, 2020), dá para entender que nas classes mais baixas, não foi possível promover o isolamento social devido às condições físicas, às situações precárias e até insalubres dos seus imóveis e da necessidade de ir atrás do sustento familiar e pagamento das contas. 
Apesar de um número expressivo de brasileiros que moram em casas, sendo maior para a população de cor da pele preta, o número gira em torno de 2,9 a 3,3 pessoas por casa (TOKARNIA, 202ob). Por outro lado, a quantidade de cômodos nos lares brasileiros não comporta o isolamento social necessário, pois em muitos lares há mais de três pessoas por cômodo (FOLHAPRESS, 2020). Para esmagar de vez a política de isolamento social e a falta de como colocá-lo em prática é que apenas II\% da população brasileira ficou de fato em home office (LISBOA, 2020). Logo, na prática o isolamento social não demonstrou o efeito necessário para reduzir o agravamento da pandemia.

\section{O GÊNERO E A PANDEMIA}

As mulheres estão sofrendo historicamente o fardo de uma sociedade machista e patriarcal, para algumas religiões a mulher é até considerada profana (HERTZ, 1980), graças a polaridade estrutural que serve como base para diversas sociedades. Mas, mesmo que a passos de formiga, gradualmente, vitórias vão sendo galgadas pelas mulheres em busca de uma sociedade mais justa, igualitária, equilibrada e sadia.

A guerra contra o machismo não está vencida, mas batalhas importantes foram conquistadas e outras vem sendo disputadas. A diminuição da mulher é crônica e vem passando através de gerações de forma hierárquica. Sobre isso, Robert Hertz traz as seguintes palavras:

Toda a hierarquia social afirma estar baseada na natureza das cosias, atribuindo-se assim eternidade e evitando mudanças e ataques de inovadores. Aristóteles justificava a escravidão pela superioridade étnica dos gregos sobre os bárbaros, e hoje o homem que se aborrece com as reivindicações feministas alega que a mulher é naturalmente inferior (HERTZ, 1980, p. 100).

Ultimamente a palavra gênero vem ganhando destaque entre a sociedade brasileira. Programas de televisão aberta cada vez mais dão espaço para o debate sobre o entendimento do gênero. Novelas veem a mostrar as mais diversas formas de expressão dele. Filmes e séries inteiras sobre o assunto. Gradualmente, a percepção da sociedade para tal começa a acontecer. 
Claramente, transgressores e criminosos ainda existem, mas já podem ser presos por tais crimes, seja por agravante de feminício, seja por homofobia.

Mesmo assim, para muitos, o assunto é relativamente novo e complexo. Buscar na bibliografia uma definição é complexo e promove um trabalho árduo a quem procura e a quem promove a definição. Definição não seria de fato a palavra, mas sim o significado. Nessa busca por tal significado de gênero, Connel (2015) presenteia com as seguintes palavras:

O gênero é a estrutura de relações sociais que se centra sobre a arena reprodutiva e o conjunto de práticas que trazem as distinções reprodutivas sobre os corpos para o seio dos processos sociais (CONNEL, 2015, p. 48).

Essa definição produz importantes consequências. Entre elas: o gênero, como outras estruturas sociais, é multidimensional. Não diz respeito apenas à identidade, nem apenas ao trabalho, nem apenas ao poder, nem apenas à sexualidade, mas a tudo isso ao mesmo tempo. Padrões de gênero podem ser radicalmente diferentes entre contextos culturais distintos, e há certamente muita variedade entre as maneiras de pensá-los, mas ainda é possível pensar (e agir) entre culturas em relação ao gênero (CONNEL, 2015, p. 49).

$\mathrm{Na}$ mesma via de fato e promovendo um olhar sobre uma definição rasa de gênero, para fins de demonstração, diferentemente do que propôs Connel (2015) com sua análise profunda do significado de gênero. Quase metade dos lares brasileiros são administrados por mulheres, as quais são conhecidas como chefes de família. Por outro lado, apesar do aumento da inserção da mulher no mercado de trabalho ainda não lhe confere a igualdade salarial.

De uma forma geral, a mulher recebe menos que o homem para desenvolver a mesma atividade quando comparados os salários de ambos os gêneros, são diferenças que circulam entre 20 a 30\%, o que no final das contas, custa muito caro e gera desigualdade para aqueles que dependem diretamente (BARBOSA; PHELIPE, 2020).

Se já não bastasse a disparidade salarial entre homens e mulheres. As mulheres que ainda têm jornadas de trabalho exaustivamente maiores que as dos homens, pois ao chegarem em seus lares, ainda promovem atividades referentes a arrumação da casa, cuidar das(os) filhas(os) e prover a alimentação deles. 
Outros dados preocupantes foram proporcionados pelo isolamento social, como por exemplo, situações de risco para grande parcela da população, principalmente para as mulheres, pois segundo Mazzi (2020) houve um aumento de 50\% no número de denúncias sobre agressões às mulheres no período de pandemia.

Novamente, o Brasil apresenta dados que vão de encontro a um dos dezessetes ODS da Agenda 2030 (2015), para o parágrafo acima, cabe ressaltar haver o ODS 5, o qual traz consigo a necessidade de alcançar a igualdade de gênero e empoderar todas as mulheres e meninas. Partindo do princípio da mudança do padrão de sustento da sociedade brasileira como supracitado por Barbosa e Phelipe (2020), nada mais pertinente do que ações governamentais que visem a equidade salarial, sendo o mínimo necessário para se começar a desenvolver as outras ações para o empoderamento das mulheres.

Por mais que aqui caiba também o ODS 5, mas também vale ressaltar que dentro do ODS ı, o qual versa sobre reduzir as desigualdades nos países e entre eles (AGENDA 2030, 2015), mas também há metas que evidenciam a necessidade de alteração de leis e políticas que visem a acabar com a desigualdade para que os cidadãos tenham de fato oportunidades de acordo com as suas necessidades, assim gerando um caminhar igualitário a todos.

Novamente, uma determinação governamental não foi de fato pensada. Promover medidas que busquem o combate às determinadas situações sem ao menos ponderar os seus efeitos colaterais é no mínimo ingenuidade (ou desconhecimento da realidade brasileira).

\section{CONSIDERAÇÕES FINAIS}

Tamanha complexidade sobre duas palavras tão pequenas, mas que emanam poder e necessitam de entendimento para serem incluídas de fato nas agendas políticas. Mas, as metas da Agenda 2030 (2015) preveem medidas a serem tomadas para que essas desigualdades características da sociedade brasileira sejam amenizadas com o passar dos anos, através de ações e investimentos em políticas públicas que possam ampliar de fato o acesso à educação, independentemente da sua raça, a qual é foco do debate no momento deste. 
A falta de noção de igualdade entre os indivíduos é forte no Brasil. Tratar as pessoas por igual não quer dizer que dará oportunidade a todas, não quer dizer que todas terão o mesmo acesso às políticas públicas, o mesmo acesso ao bem-estar, à educação de qualidade, à saúde, ao lazer. Acreditar que todas as pessoas são iguais é mau-caratismo. O conceito de cidadania do modelo Republicano (PINHÃO; MARTINS, 20I6) é vexatório. Vergonhoso. Pensar que abaixo dos Trópicos todos são iguais é nauseante.

Todas as medidas tomadas por governos deveriam considerar as diferenças sociais que existem entre os gêneros e raças, pensar sempre nas diferenças vale para elevar a equidade e trazer benefícios a todos os envolvidos, pois só assim de fato serão atendidas as diferenças que o ODS -5 buscará diminuir durante a aplicação de suas ações (CARVALHO; JAVONI; SEIXAS, 2020).

Empoderar parece ser a palavra ideal. A emancipação do ser humano através do empoderamento é essencial para que todos lutem por direitos iguais levando em consideração as diferenças existentes entre gênero e raça (BAQUERO, 2012). Segundo Paulo Freire (I986) não é possível promover a autolibertação, pois a libertação é um ato social.

É através do conhecimento da população, através da imersão da sociedade na situação em que vivem, só assim a percepção poderá acontecer. É através da imersão que se consegue emergir. Emergir sábio da situação em que se vive. Emergir consciente da luta que tem que traçar para que todos tenham melhores qualidades de vida em todos os sentidos. Ninguém liberta ninguém. Os homens se libertam (FREIRE, 2019).

O artigo 5..$^{\mathrm{O}}$ da Constituição Federal diz que todos são iguais perante a Lei, sem distinção de qualquer natureza (BRASIL, 1988). A Princípio parece ser o ideal se todos realmente tivessem as mesmas condições de acesso a tudo que se tem disponível para o desfrute do cidadão. Mas isso não ocorre. A disparidade de acesso entre gênero e raça é ameaçadora, cruel e violenta. Os brasileiros não são todos iguais e nem deveriam ser, a heterogeneidade da nação é fantástica em caráter cultural, o país é continental, mas igualmente gigante é a falta de oportunidade. 


\section{REFERÊNCIAS BIBLIOGRÁFICAS}

AGENDA 2030. 2015. Plataforma Agenda 2030: Acelerando as transformações para a Agenda 2030 no Brasil. Disponível em: http://www.agenda2030.com.br/. Acesso em: 25 abr. 202I.

ANTUNES, A. Comunicação e informação. Notícias. As redes municipais de educação diante da pandemia. FIOCRUZ. Rio de Janeiro, 2020. Disponível em: https://portal.fiocruz.br/noticia/redes-municipais-de-educacao-diante-da-pandemia. Acesso em: 25 abr. 2021.

BAQUERO, R. V. A. Empoderamento: instrumento de emancipação social? - uma discussão conceitual. Revista Debates, Porto Alegre, v. 6, n. I, p. 173-187, jan-abr. 2012.

BARBOSA, M.; PHELIPE, A. Economia. Quase metade dos lares brasileiros são sustentados por mulheres: percentual de casa com comando feminino salte de 25\% em 1995 para $45 \%$ em2or8, com inserção no mercado de trabalho. Estado de Minas. Brasília, 2020. Disponível em: https://www.em.com.br/app/noticia/economia/2020/02/16/internas_economia,I122167/quase -metade-dos-lares-brasileiros-sao-sustentados-por-mulheres.shtml. Acesso em 25 abr. 2021.

BITTENCOURT, J. Início. Coronavírus. Países que, assim como o Brasil de Bolsonaro, negligenciaram o coronavírus, sofrem consequências: Quem se antecipou, como a China, Cuba e a Coreia do Sul, controlou a crise e quem a subestimou, como a Itália e os EUA, começa a pagar um preço caro. Revista Fórum, 2020. Disponível em: https://revistaforum.com.br/brasil/coronavirus/paises-que-assim-como-o-brasil-debolsonaro-negligenciaram-o-coronavirus-sofrem-consequencias/. Acessado em: 25 abr. 202I.

BRASIL. Constituição(1988). Constituiçãoda República Federativa do Brasil. Brasília, DF: Senado Federal: Centro Gráfico, 1988. 
BRASIL. Ministério da Educação. Instituto Nacional de Estudos e Pesquisas Educacionais Anísio Teixeira - INEP. Estudo detalha situação do analfabetismo no País. Brasília, 2003. Disponível em: http://inep.gov.br/artigo//asset_publisher/B4 ${ }_{4} \mathrm{QV}_{92} \mathrm{FY}_{7} \mathrm{Bv} /$ content/estudo-detalha-situacao-do-analfabetismo-nopais/21206. Acesso em: 25 abr. 2021.

BRASIL. Ministério da Educação. Portaria no 343, de 17 de março de 202ob: Dispões sobre a suspensão das aulas presenciais por aulas em meios digitais enquanto durar a situação de pandemia do Novo Coronavírus - COVID-i9. Disponível em: https://www.in.gov.br/en/web/dou/-/portaria-n-343-de-17-de-marco-de-2020-248564376. Acesso em: 25 abr. 2021.

BRASIL. Ministério da Saúde. Portaria no 356, de il de março de 2020a: Dispõe sobre a regulamentação e operacionalização do disposto na Lei no 13.979 , de 6 de fevereiro de 2020, que 953 estabelece as medidas para enfrentamento da emergência de saúde pública de importância internacional decorrente do coronavírus (COVID-I9). Disponível em: https://www.in.gov.br/en/web/dou/-/portaria-n-356-de-II-de-marco-de-2020-247538346.

Acesso em: 25 abr. 2021.

BULUT, C.; KATO, Y. Epidemiolgy of COVID-19. Turkish Journal of Medical Sciences. 2020. 50: $\quad$ p. $563 \quad$ - $570 . \quad$ Disponível em: https://journals.tubitak.gov.tr/medical/abstract.htm?id=27232. Acesso em: 25 abr. 2021.

CARVAlHO, A. F.; JAVONI, L. A. R.; SEIXAS, S. R. C. Mudanças climáticas, sustentabilidade e direitos humanos: algumas considerações sobre gênero e raça. Momentum, Atibaia, v. I, n. I8, p. I-15, 2020. 
CERVO, A. L.; BERVIAN, P. A.; SILVA, R. Metodologia científica. 6 ed. São Paulo: Pearson Prentice Hall, 2007.

CONNEL, R. Gênero: Uma Perspectiva Global. São Paulo: editora NVersos, p. 25- 50. 2015.

DANIEL, M. Os difíceis percursos do transporte público no Brasil. Revista Educação, 2020. Disponível em: https://revistaeducacao.com.br/2020/or/2I/transporte-escolar-brasil/. Acesso em: 25 abr. 2021.

FOLHAPRESS. Mais de II milhões no Brasil moram em casas superlotadas. Portal o Tempo. Belo Horizonte, 2020. Disponível em: https://www.otempo.com.br/brasil/mais-de-IImilhoes-no-brasil-moram-em-casas-superlotadas-1.2317766. Aceso em: 25 abr. 2021.

FREIRE, P. Pedagogia do oprimido, Rio de Janeiro: Paz e Terra, 2019.

FREIRE, P.; SHOR, I. Medo e ousadia - o cotidiano do professor, Rio de Janeiro: Paz e Terra, 1986.

HERTZ, R. 1980 [1909]. A preeminência da mão direita: um estudo sobre a polaridade religiosa. Religião e Sociedade, 6: 99-128

INLOCO. Mapa brasileiro da COVID-19. Recife, 202I. Disponível em: https://mapabrasileirodacovid.inloco.com.br/pt/. Acesso em: 25 abr. 202I.

LISBOA, V. IPEA: percentual de brasileiros em home office cai para $11,7 \%$ em julho. AgênciaBrasil. Rio de Janeiro, 2020. Disponível em: 
https://agenciabrasil.ebc.com.br/geral/noticia/2020-09/ipea-percentual-de-brasileiros-emhome-office-cai-para-II7-em-julho. Acesso em: 25 abr. 2021.

MADEIRO, C. Negros são 75\% entre os mais pobres; brancos são 70\% entre os mais ricos. Uol. Maceió, 2019. Disponível em: https://noticias.uol.com.br/cotidiano/ultimasnoticias/2019/II/13/percentual-de-negros-entre-Io-mais-pobre-e-triplo-do-que-entre-maisricos.htm. Acesso em: 25 abr. 2021

MAZZI, C. Violência doméstica dispara na quarentena: como reconhecer, proteger e denunciar. $\mathrm{O}$ Globo. Rio de Janeiro, 2020. Disponível em: https://oglobo.globo.com/sociedade/coronavirus-servico/violencia-domestica-dispara-naquarentena-como-reconhecer-proteger-denunciar-24405355. Acesso em: 25 abr. 202I.

OPAS - Organização Pan-Americana da Saúde. OMS afirma que COVID-ı9 é agora caracterizada como pandemia. Brasília, 2020. Disponível em: https://www.paho.org/bra/index.php?option=com_content\&view=article\&id=6120:omsafirma-que-covid-ı-e-agora-caracterizada-como-pandemia\&Itemid=812. Acesso em: 25 abr. 2021.

PINHÃO, F.; MARTINS, I. Cidadania e ensino de ciências: questões para o debate. Ens. Pesqui. Educ. Ciênc. Belo Horizonte, v. I8, n. 3, p. 9-29. Dec. 2016.

SANTOS, D. J. S. et al. Raça versus etnia: diferenciar para melhor aplicar. Dental Press J Orthod. v. I5, n. 3. p. I2I-4. maio - jun, 2010.

TOKARNIA, M. Um em cada quatro brasileiros não tem acesso à internet, mostra pesquisa: número representa 46 milhões de que não acessam a rede. AgênciaBrasil. Rio de Janiero, 
2020a. Disponível em: https://agenciabrasil.ebc.com.br/economia/noticia/2020-04/um-emcada-quatro-brasileiros-nao-tem-acesso-internet. Acessado em: 25 abr. 202I.

TOKARNIA, M. A maioria dos brasileiros vivem em casa e é dona do próprio imóvel. AgênciaBrasil. Rio de Janeiro, 2020b. Disponível em: https://agenciabrasil.ebc.com.br/economia/noticia/2020-05/maioria-dos-brasileiros-moraem-casa-e-e-dona-do-imovel-mostraibge\#: :text=No\%2opa\%C3\%ADs\%2C\%2oem\%2ocada\%2odomic\% $\%$ C3\%ADlio,popula\%C $3 \% \mathrm{~A}_{7}$

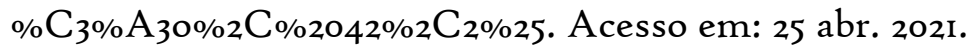

VALENTE, J. Brasil tem 134 milhões de usuários de internet: a maioria acessa a internet pelo celular. AgênciaBrasil. Brasília, 2020. Disponível em: https://agenciabrasil.ebc.com.br/geral/noticia/2020-05/brasil-tem-I34-milhoes-de-usuariosde-internet-aponta-pesquisa. Acesso em: 25 abr. 2021.

WORLD HEALTH ORGANIZATION - WHO. Coronavirus. 2021. Disponível em: https://www.who.int/health-topics/coronavirus\#tab=tab_I. Acesso em 25 abr. 202I. 